\title{
Genome-wide analysis of IncRNA and mRNA expression and endogenous hormone regulation during tension wood formation in Catalpa bungei
}

Yao Xiao', Fei Yi ${ }^{1}$, Juanjuan Ling ${ }^{1}$, Guijuan Yang ${ }^{1}$, Na Lu', Zirui Jia' ${ }^{1}$, Junchen Wang ${ }^{1}$, Kun Zhao ${ }^{2}$, Junhui Wang ${ }^{1}$ and Wenjun $\mathrm{Ma}^{1 *}$

\begin{abstract}
Background: Phytohormones are the key factors regulating vascular development in plants, and they are also involved in tension wood (TW) formation. Although the theory of hormone distribution in TW formation is widely supported, the effects of endogenous hormones on TW formation have not yet been assessed. In this study, TW formation was induced in Catalpa bungei by artificial bending. The phytohormone content of TW, opposite wood (OW) and normal wood (NW) was determined using liquid chromatography-mass spectrometry (LC-MS), and transcriptome sequencing was performed. The hormone content and related gene expression data were comprehensively analyzed.
\end{abstract}

Results: The results of analyses of the plant hormone contents indicated significantly higher levels of cis-zeatin (cZ), indoleacetic acid (IAA) and abscisic acid (ABA) in TW than in OW. Genes involved in the IAA and ABA synthesis pathways, such as ALDH (evm.model.group5.1511) and UGT (evm.model.scaffold36.20), were significantly upregulated in TW. and the expression levels of ARF (evm.model.group5.1332), A-ARR (evm.model.group0.1600), and TCH4 (evm.model.group2.745), which participate in IAA, CZ and Brassinolide (BR) signal transduction, were significantly increased in TW. In particular, ARF expression may be regulated by long noncoding RNAs (IncRNAs) and the HD-ZIP transcription factor ATHB-15.

Conclusions: We constructed a multiple hormone-mediated network of C. bungei TW formation based on hormone levels and transcriptional expression profiles were identified during TW formation.

Keywords: Tension wood, Catalpa bungei, Phytohormones, IncRNA, Regulatory network

\footnotetext{
* Correspondence: mwilx.163@163.com

'State Key Laboratory of Tree Genetics and Breeding, Key Laboratory of Tree Breeding and Cultivation of State Forestry and Grassland Administration,

Research Institute of Forestry, Chinese Academy of Forestry, Beijing 100091,

PR China

Full list of author information is available at the end of the article
}

(c) The Author(s). 2020 Open Access This article is licensed under a Creative Commons Attribution 4.0 International License, which permits use, sharing, adaptation, distribution and reproduction in any medium or format, as long as you give appropriate credit to the original author(s) and the source, provide a link to the Creative Commons licence, and indicate if changes were made. The images or other third party material in this article are included in the article's Creative Commons licence, unless indicated otherwise in a credit line to the material. If material is not included in the article's Creative Commons licence and your intended use is not permitted by statutory regulation or exceeds the permitted use, you will need to obtain permission directly from the copyright holder. To view a copy of this licence, visit http://creativecommons.org/licenses/by/4.0/. The Creative Commons Public Domain Dedication waiver (http://creativecommons.org/publicdomain/zero/1.0/) applies to the data made available in this article, unless otherwise stated in a credit line to the data. 


\section{Background}

Trees have highly lignified stems, which are the source of wood. Wood is the main material used for production and homebuilding. Strategies for improving wood yields and quality have historically been the focus of tree breeders. The discovery of reaction wood provided a new approach for use by researchers to study the mechanism of wood formation $[1,2]$. Reaction wood is classified into tension wood (TW) and compression wood according to the orientation of the stress in the xylem (angiosperms generate stronger tension stresses on the upper side of the stem, and gymnosperms generate stronger compression stresses on the lower side of the stem) [3]. TW usually exists in asymmetric xylem and exhibits extremely high growth stress levels. Trees regulate the stem growth direction through eccentric growth [4]. The physical and chemical properties of TW are very different from normal wood (NW). Mechanically, TW has an unusually high tensile strength and dry shrinkage, but its compressive strength is very low $[5,6]$. Regarding its chemical composition, studies have reported a low lignin content and high arabinogalactan protein content in TW $[7,8]$. The processing of wood containing TW is fraught with problems, such as cracking. The processing of wood containing TW is fraught with problems such as cracking restricting its use as high-quality timber. However, TW provides the basis for exploring the processes of wood development that result in unique physical and chemical properties. Therefore, studies examining the mechanism of TW formation are very important.

The mechanism of TW formation was studied as early as the middle of the twentieth century, but the cause of TW formation has not been assessed. Researchers have formulated (1) growth stress hypotheses [9], (2) the gravitational response theory [10], and (3) the auxin distribution theory to explain TW formation. The auxin distribution theory has been accepted by many scholars, and its principle is that the distribution of endogenous hormones is not balanced between the upper and lower stems due to the effects of gravity when tree growth is not vertical. This imbalance leads to cell division in the upper or lower stem, widening of the growth ring, and the production of specialized cell structure, resulting in TW formation [11, 12]. The anatomy of TW is vastly different from NW. Generally, TW is described as having small vessels and a high ratio of fibers to vessels and a gelatinous layer (G-layer) is included in the fiber lumen in some tree species $[13,14]$. The specialization of these cells and tissues is often regulated by endogenous hormones. According to Love et al. (2009), characteristics of xylem treated with ethylene are similar to the characteristics of TW, both of which generate eccentric growth and decrease the proportion of vessels [15].
Felten et al. (2018) compared the xylem development of wild-type and ethylene-insensitive hybrid poplars following ethylene application and found that ethylene activated some transcription factors and triggered G-layer formation [16]. Moreover, ethylene was recently shown to be a key phytohormone regulating TW formation [14]. Gibberellin (GA) enhances the activity of cambium [17], and xylem specialization may be caused by changes in vascular cambium function. Gibberellin has consistently been shown to promote TW formation [18, 19]. Part of the regulatory mechanism has also been explained as follows: gibberellin induces the degradation of the PtRGA protein, alleviates the inhibition of PtFLA by PtRGA, promotes PtFLA gene expression and eventually induces poplar TW formation [20]. However, other studies have not reported a significant correlation between gibberellin and G-layer differentiation [21]. In addition, exogenous indoleacetic acid (IAA) exerts a significant regulatory effect on xylem formation. After IAA treatment, the secondary xylem of hybrid poplar forms TW, with a concomitant increase in the expression of the genes related to auxin transport and cellulose biosynthesis [22]. As shown in the study by Hellgren et al. (2004), the endogenous IAA content in TW is not significantly different from that in NW but was higher than in OW [23]. However, some studies did not reach this conclusion; instead, a significant difference in the endogenous IAA content was not observed between TW and OW and the authors proposed that the change in the IAA distribution did not cause TW formation [24]. Researchers have not clearly determined whether the effect of endogenous IAA on TW formation is positive or negative [3]. Most studies focus on the regulation of plant growth by a single hormone but rarely discuss the regulation of growth mediated by interactions among hormones. On the other hand, a large number of studies have also explored gene expression during TW formation. Genes related to cell wall formation expressed in TW, such as cellulose synthase and pectin metabolism genes, displayed significant differences from genes expressed in NW or OW [25-27]. Gerttula et al. (2015) generated genome-wide transcriptomes for trees in which gene expression was perturbed by gravistimulation, GA treatment, and modulation of ARK2 expression, and the transcription factor ARK2 altered TW formation in poplar by regulating gibberellin signaling [28]. In addition to transcription factors, long noncoding RNAs (lncRNAs) are also involved in TW formation as transcriptional regulators. Chen et al. (2014) conducted the genome-scale identification and characterization of lncRNAs in TW of Populus and the authors documented that predicted target genes of lncRNAs are involved in many biological processes, such as cellulose, lignin and gibberellin biosynthesis, suggesting potential roles of 
lncRNAs in wood formation [29]. Although plant hormones are key factors regulating TW formation, the underlying expression pattern has not been elucidated, particularly the lncRNA expression pattern. The identification of this pattern is one of the aims of our study.

Catalpa. bungei has a straight stem with a high wood density, high hardness and strong bending resistance and is considered a valuable commercial tree species [30]. An analysis of the wood formation mechanism of C. bungei will facilitate the genetic improvement of its timber. The existence of TW makes the wood prone to distortion and cracking during wood processing. These distortions also substantially hinder the use of precious timber. Therefore, studies examining the pattern of TW formation under physiological conditions and the associated molecular mechanisms are of great practical value for reducing the loss caused by defects due to TW and improving the quality and utilization of wood. Plant growth traits are often controlled by multiple hormones and analyses of the actions of multiple hormones may be a reliable approach for determining the underlying mechanisms. Thus, in the present study, we induced
TW formation in C. bungei by artificial bending using a clone with high wood density and hardness (Additional file 1). The endogenous hormone levels and the transcriptomes of TW, opposite wood (OW) and NW were investigated to reveal the potential mechanisms by which multiple hormones regulate TW formation via hormone synthesis and signal transduction.

\section{Results}

The development of fibers and vessels in the TW of $C$. bungei

After artificial bending, the xylem development in the upper bent stem in C. bungei was significantly altered. The vessel size was smaller and the vessel length and width were significantly smaller in TW than in the OW and NW. However, in TW, the vessel length:width ratio was significantly larger than in OW and NW by approximately 1.4-fold, and the vessels had a long oval shape, which was in contrast to the round vessels in OW and NW (Fig. 1a-c, g and h). The fiber cell lumen of C. bungei TW did not contain a G-layer. In addition, the secondary wall thickening was blocked, leading to a thinner

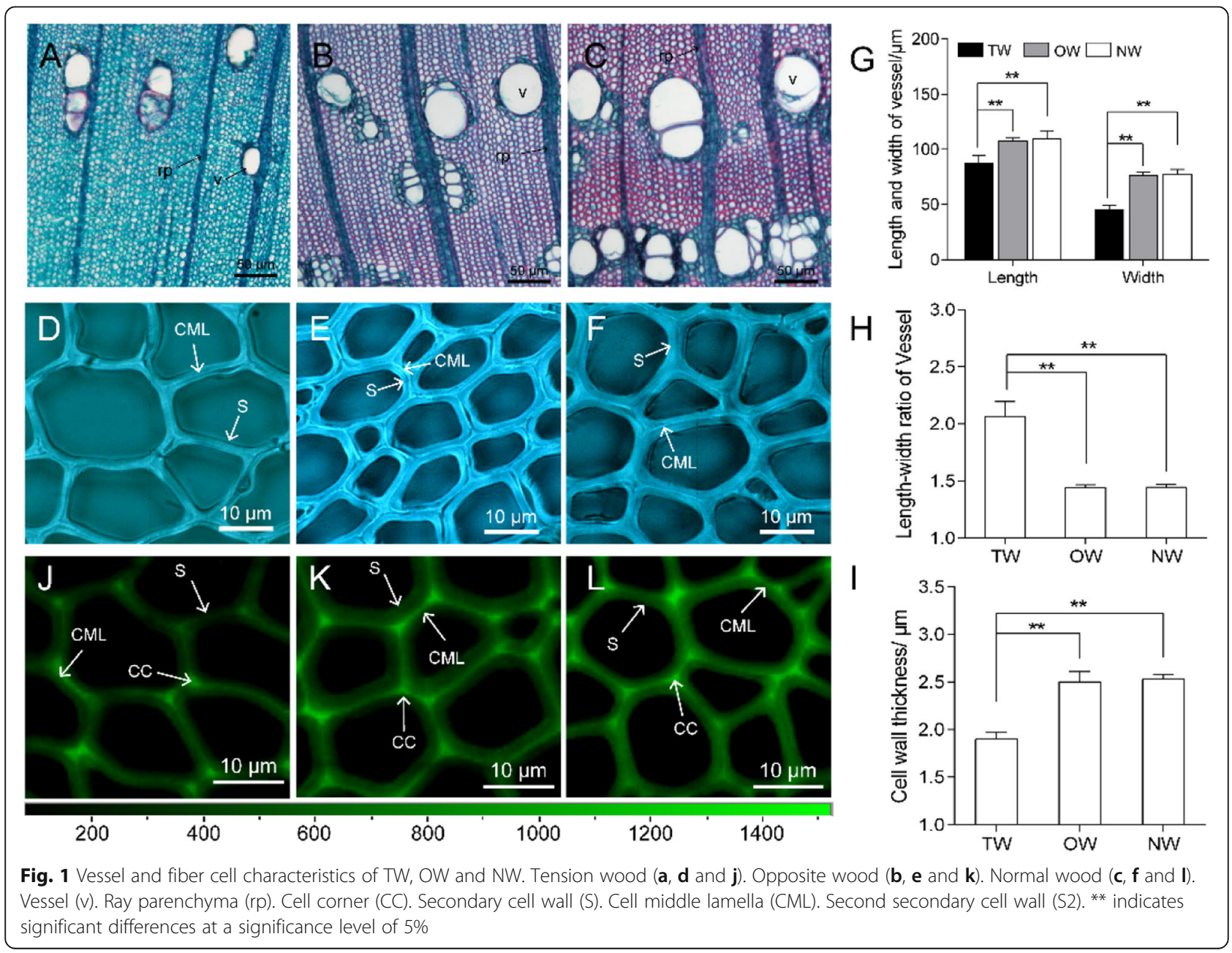


secondary wall (Fig. 1i). Moreover, the Raman spectroscopy and microscopy imaging results revealed reduced lignification of the TW fiber cells (Fig $1 \mathrm{j}-\mathrm{l}$ ).

\section{Content of endogenous hormones in TW, OW and NW}

In this study, the contents of six major plant hormones-auxin, zeatin, abscisic acid, jasmonic acid, salicylic acid and gibberellin - were determined using liquid chromatography-mass spectrometry (LC-MS). The statistical analysis revealed approximately $58.24 \%$ higher contents of indoleacetic acid (IAA), methyl indol-3ylacetate (ME-IAA) and indole-3-carboxylic acid (ICA) in TW than in OW, but the concentrations did not significantly differ from those in NW (Fig. 2). In addition, the cis-zeatin (cZ) content in TW was significantly higher than in OW and NW. Furthermore, a significantly higher abscisic acid (ABA) level was detected in TW than in OW and NW, and significantly higher JA and SA levels were detected in NW than in TW and OW. Here, a significantly higher GA1 level was observed in OW than in TW and NW, and the highest GA7 level was detected in TW, while the GA3 level did not differ significantly among the three wood types (Fig. 3).

\section{Differential expression of mRNAs and IncRNAs}

We measured the transcript abundance in TW, OW and NW to further analyze the internal regulatory mechanism of TW formation. A total of 8998 novel lncRNAs were detected. Intergenic lncRNAs were the most abundant type, Overall, 554 antisense lncRNAs were detected, but no intronic lncRNAs were identified (Additional file 2). According to the transcript expression analysis (Fig. 4), 384 and 410 mRNAs were upregulated and downregulated only in TW/NW, respectively. There were Five hundred forty-seven mRNAs significantly upregulated and 259 mRNAs were significantly downregulated in TW compared with OW. One hundred fifteen and 124 lncRNAs were significantly upregulated in TW compared with NW and OW, respectively. Seventyseven and 87 lncRNAs were significantly downregulated in TW/NW and TW/OW, respectively. Thirty-nine of these IncRNAs were upregulated in two comparison

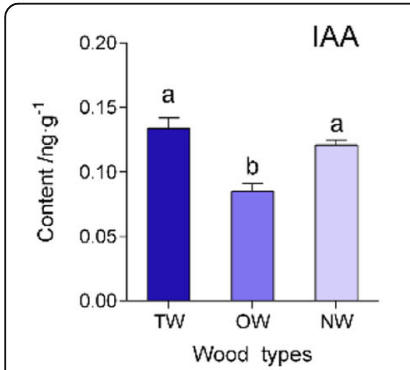

IP

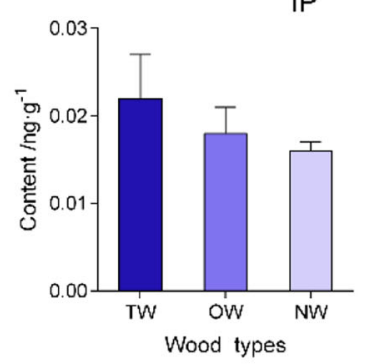

JA

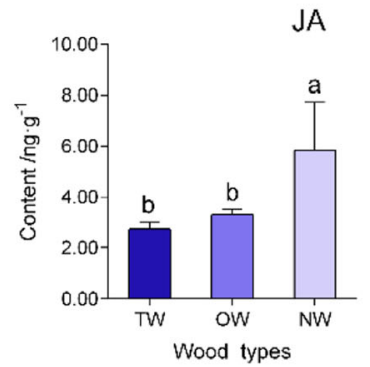

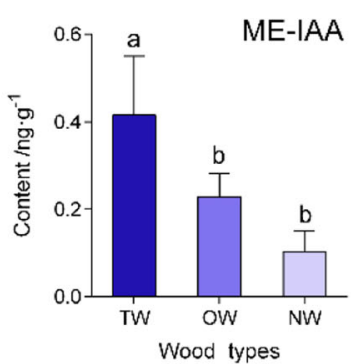

$c Z$

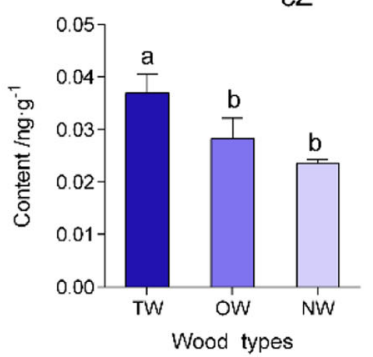

JA-ILE

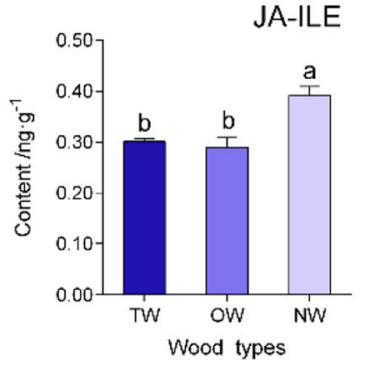

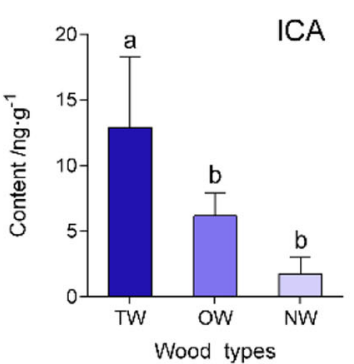

$\mathrm{DZ}$

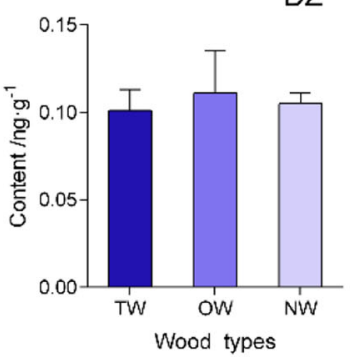

H2JA

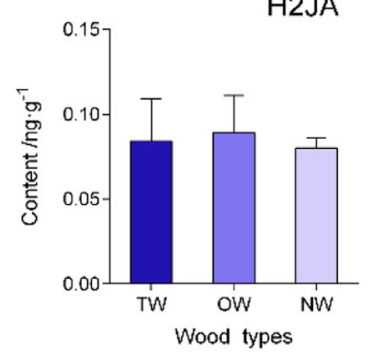

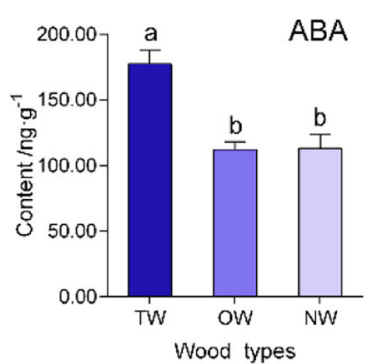

tZ

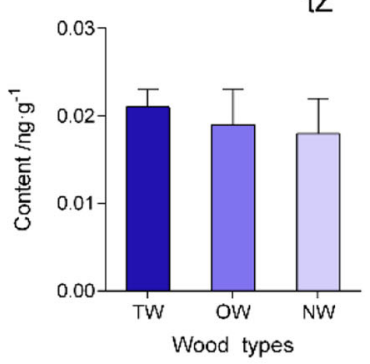

SA

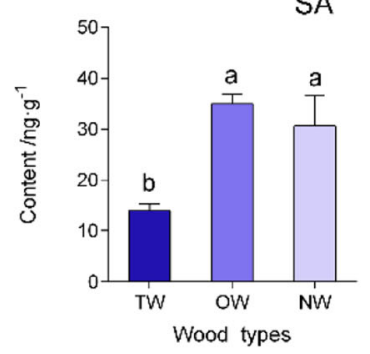

Fig. 2 Phytohormone levels in different wood types. The different letters indicate significant differences at a significance level of 5\%. IAA: indoleacetic acid, ME-IAA: methyl indol-3-ylacetate, ICA: indole-3-carboxylic acid, ABA: abscisic acid, IP: N6-( $\triangle 2$-isopentenyl) adenine, cZ: cis-zeatin, DZ: dihydrozeatin, tZ: trans-zeatin, JA: jasmonic acid, JA-ILE: jasmonoyl-isoleucine, H2JA: dihydrojasmonic Acid, SA: salicylic acid 


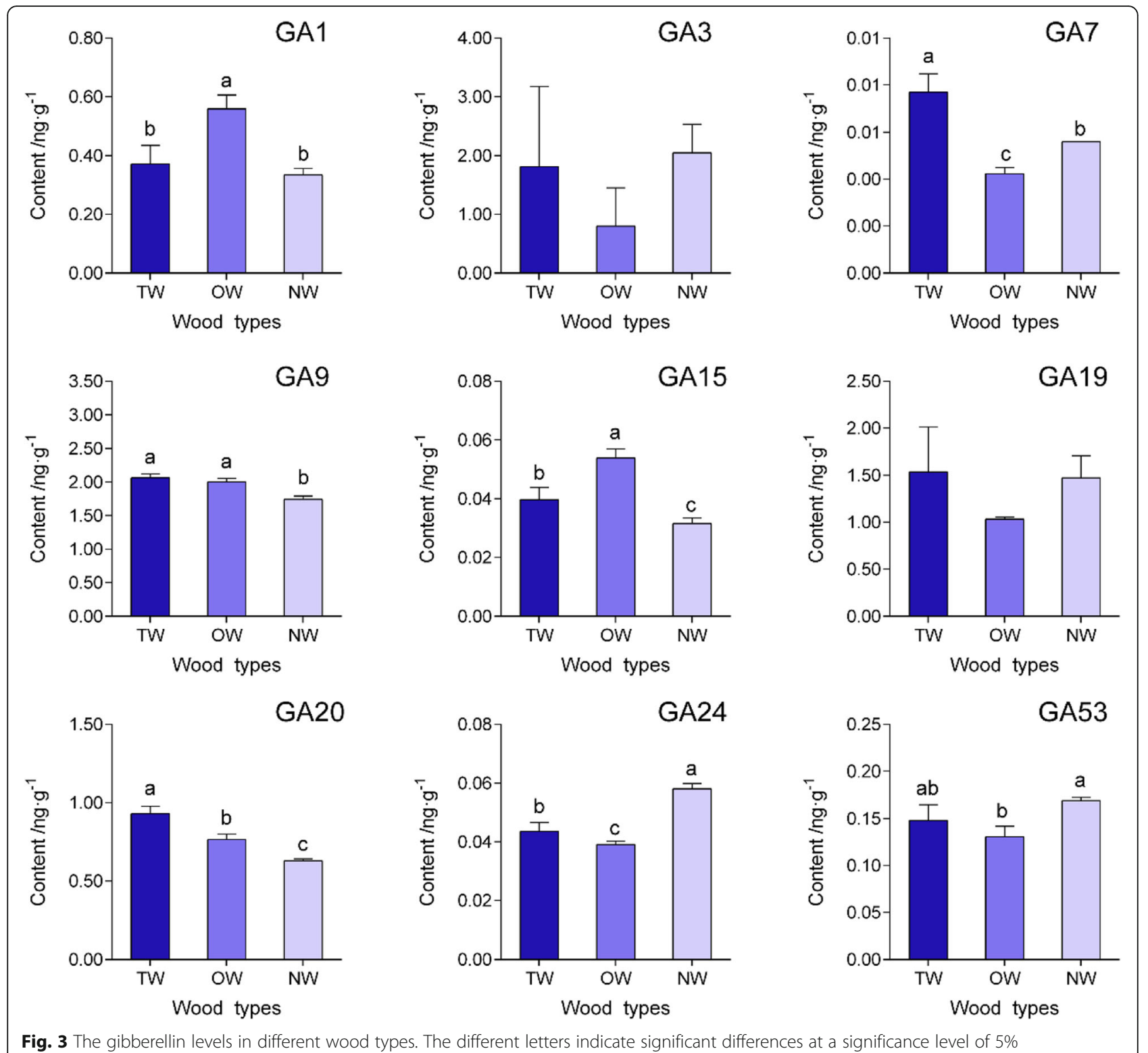

Fig. 3 The gibberellin levels in different wood types. The different letters indicate significant differences at a significance level of 5\%

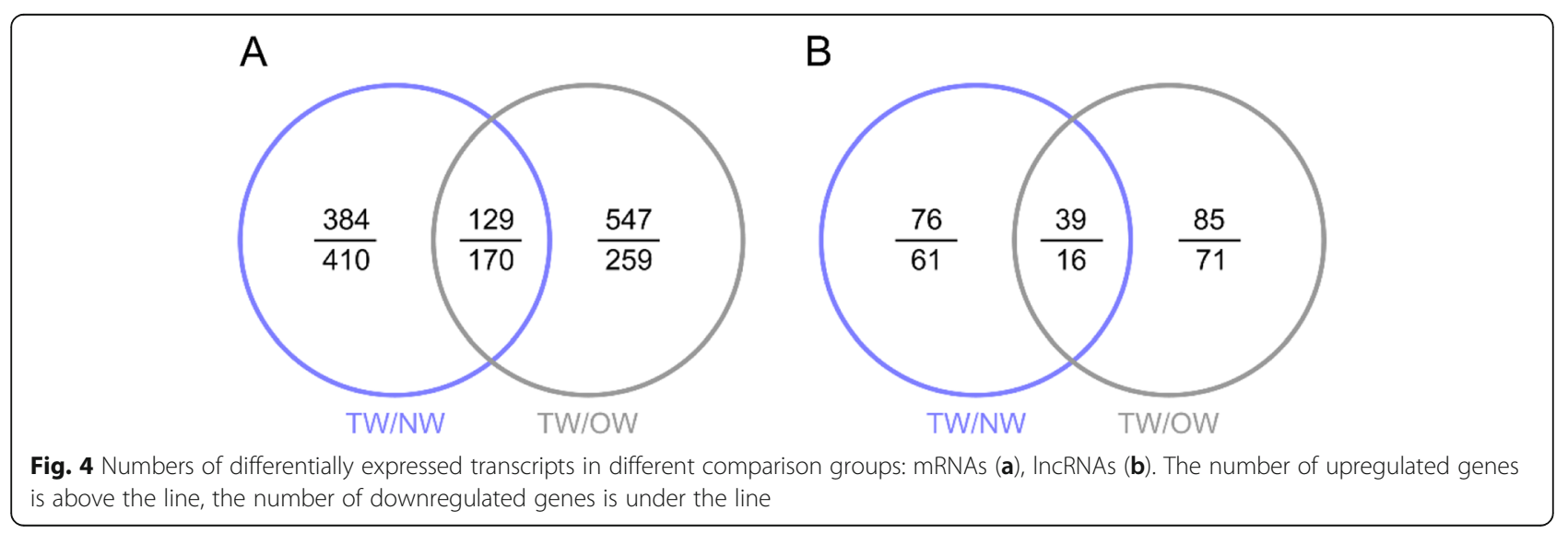


groups and 16 lncRNAs were downregulated in two comparison groups.

\section{Analysis of differentially expressed genes (DEGs) involved in plant hormone biosynthesis and signal transduction pathways}

According to the Kyoto Encyclopedia of Genes and Genomes (KEGG) database and targeted analysis of the plant hormone synthesis pathway and signal transduction pathway, the DEGs in the TW/NW and TW/OW comparison groups (Fig. 5a-b) with an expression level threshold of $($ FPKM $)>1$, fold change $>1.5$ or $<-1.5$ and a $P$ value $<$ 0.05 were selected (Additional file 3 ). In these two comparison groups, 5 and 13 DEGs related to plant hormone biosynthesis and catabolism were significantly upregulated in the TW/NW and TW/OW comparison groups, respectively. Additionally, more genes involved in plant hormone signal transduction were significantly differentially expressed between TW and NW. (Additional file 3).

In this study, a significantly higher cZ level was detected in TW than in OW and NW, and the genes responding to zeatin were also significantly differentially expressed (Figs. 2; 5A-B and 7). A-ARR (evm.model.group0.1600) transcript was significantly upregulated in TW compared with both
NW and OW. The CRE, AHP and B-ARR genes were downregulated in TW compared with NW. On the other hand, the BR receptor gene BRI1 (evm.model.group6.919) was significantly downregulated in TW compared with NW. However, in the TW/OW comparison, CYP90B1 (evm.model.group6.851), which catalyzes the synthesis of $\mathrm{BR}$, and the TCH4 transcript (evm.model.group2.745), which responds to $B R$, were significantly upregulated. (Figs. $5 \mathrm{~b}$ and 7). In addition, because the IAA level was significantly different between TW and OW, some transcripts involved in IAA synthesis and signal transduction pathways were also significantly differentially expressed in the TW/ NW and TW/OW comparison groups. The expression of $A L D H 1$ (evm.model.group5.1511), which encodes the enzyme that catalyzes the conversion of indole-3acetaldehyde to IAA, was upregulated in TW compared with NW and OW (Fig. 6). UGT1 (evm.model.scaffold36.20), whose protein product catalyzes the production of the IAA precursor indolylmethyl-desulfoglucosinolate, was upregulated in TW compared with OW. IAAI (TCONS_00040006) was upregulated in TW compared with both NW and OW, ARF5 (evm.model.group5.1332) was upregulated in TW compared with OW, and $4 A R F s$ were downregulated in TW compared with NW (Fig. 7).

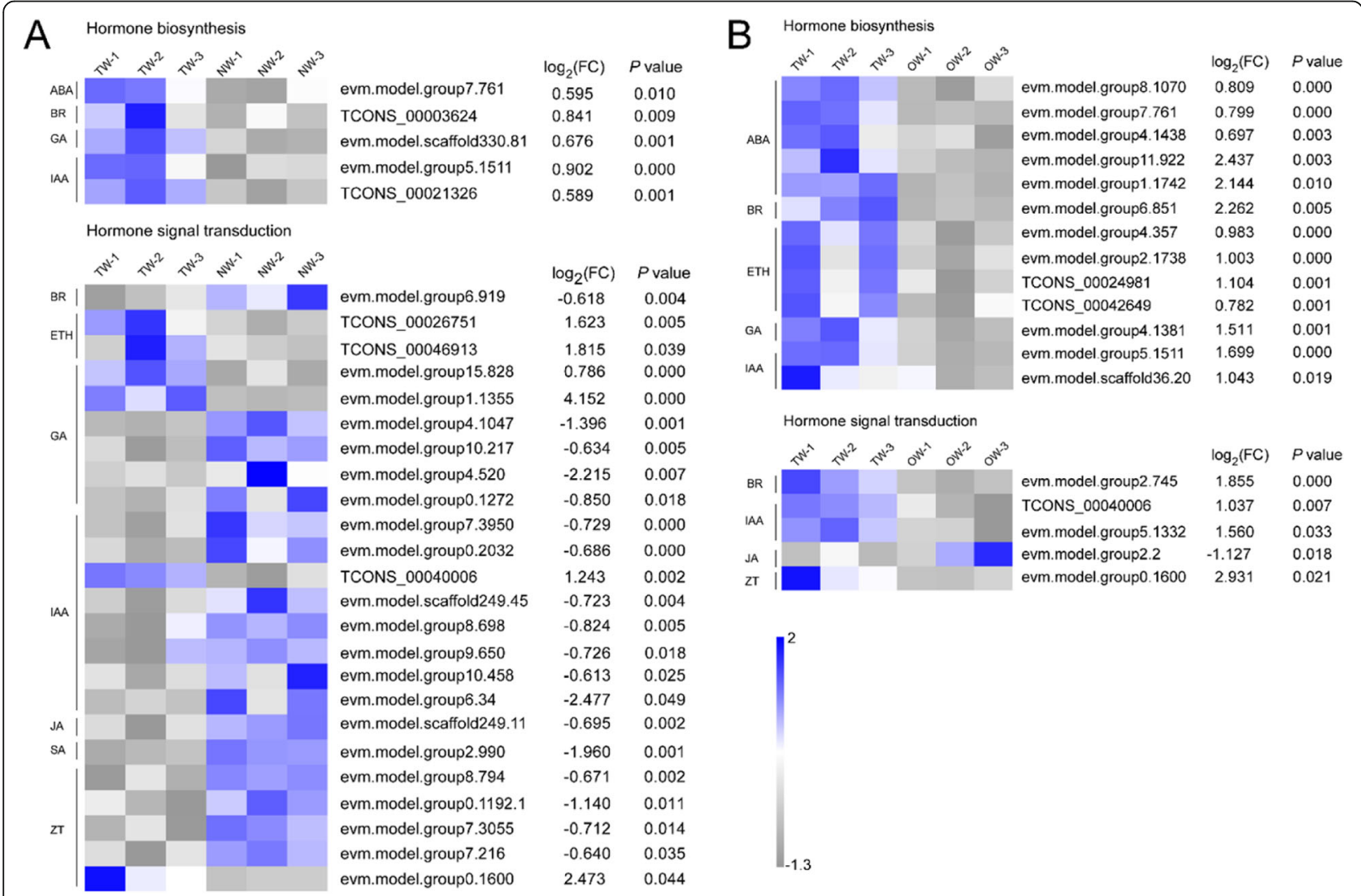

Fig. 5 Expression levels of transcripts involved in phytohormone synthesis and signal transduction pathways in the TW/NW (a) and TW/OW (b) comparison groups. (FC), fold change value 


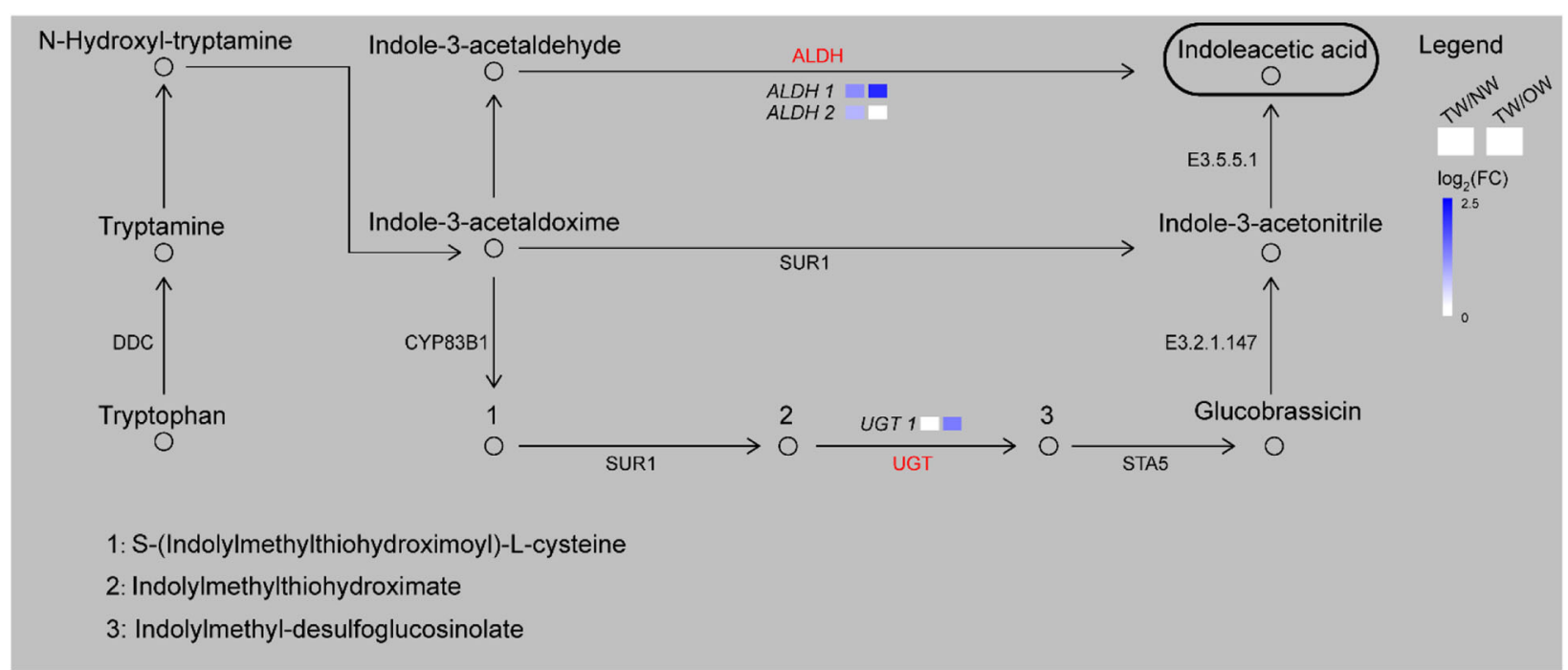

Fig. 6 The differentially expressed transcripts involved in auxin synthesis. (FC), fold change value

Gene ontology (GO) terms and KEGG pathway enrichment analyses of IncRNA target genes

The RNA-sequencing (RNA-seq) results showed that most lncRNAs were involved in cis regulation, followed sequentially by trans regulation and antisense regulation.
The analysis of significantly enriched GO terms showed that the lncRNAs mainly regulated the expression of genes involved in nucleotide binding, cell wall and peripheral structure development (Table 1). The results of the KEGG pathway enrichment analysis of target genes

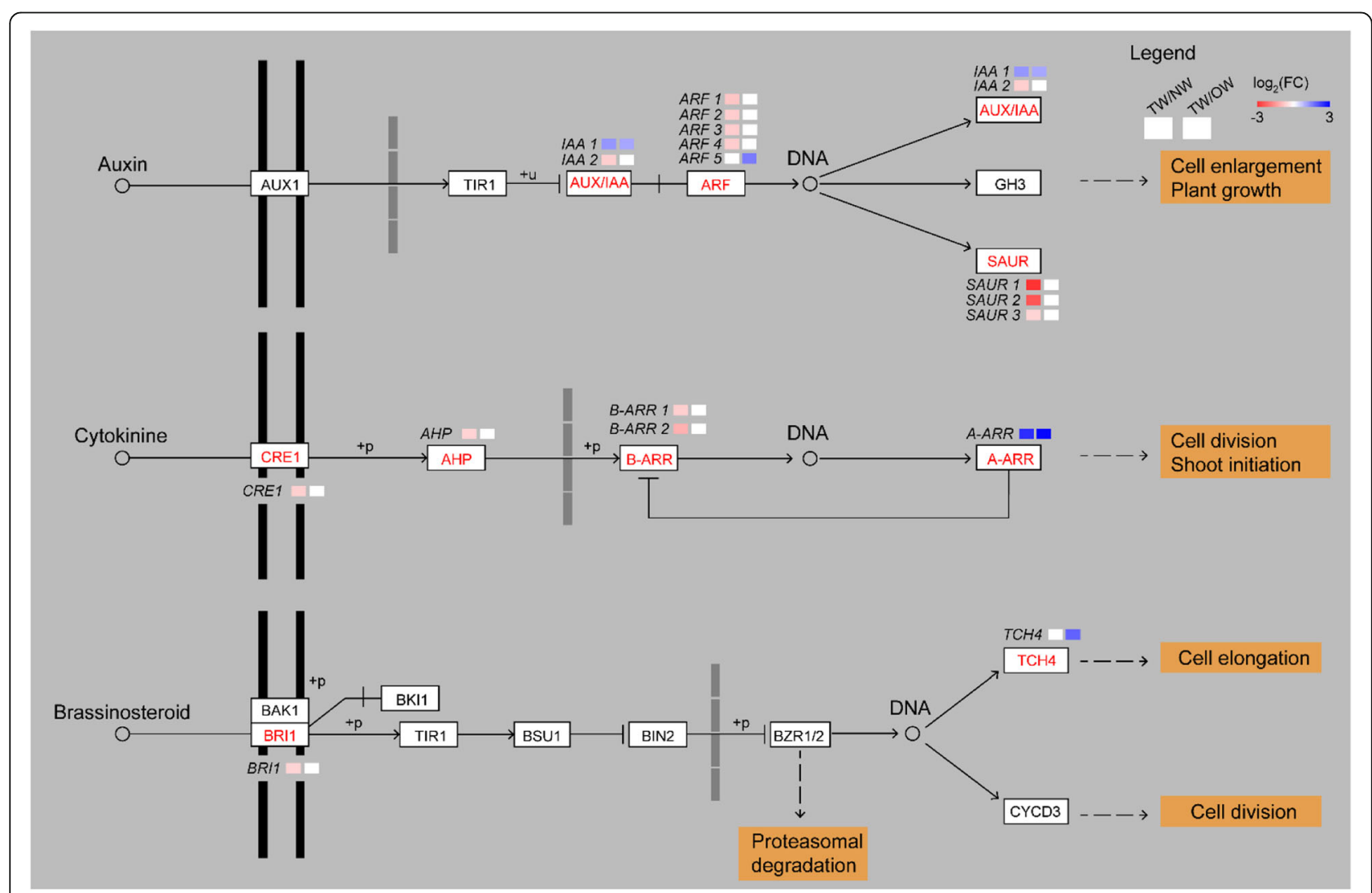

Fig. 7 The differentially expressed transcripts involved in the plant hormone signal transduction pathway. (FC), fold change value 
Table 1 Analysis of enriched GO terms for the IncRNA-targeted mRNAs

\begin{tabular}{|c|c|c|c|c|c|}
\hline GO term & GO ID & Description & GeneRatio (2907) & BgRatio (15307) & P.adjust \\
\hline \multicolumn{6}{|l|}{ Cis regulation } \\
\hline \multirow[t]{11}{*}{ Molecular Function } & GO:0017076 & purine nucleotide binding & $507(17.44 \%)$ & $2188(14.29 \%)$ & 0.000025 \\
\hline & GO:0030554 & adenyl nucleotide binding & $456(15.69 \%)$ & $1946(12.71 \%)$ & 0.000025 \\
\hline & GO:0032555 & purine ribonucleotide binding & $496(17.06 \%)$ & 2139 (13.97\%) & 0.000025 \\
\hline & GO:0032553 & ribonucleotide binding & $502(17.27 \%)$ & $2172(14.19 \%)$ & 0.000025 \\
\hline & GO:0032559 & adenyl ribonucleotide binding & $446(15.34 \%)$ & $1906(12.45 \%)$ & 0.000027 \\
\hline & GO:0005515 & protein binding & $703(24.18 \%)$ & 3169 (20.7\%) & 0.000029 \\
\hline & GO:0043168 & anion binding & $556(19.13 \%)$ & $2469(16.13 \%)$ & 0.000102 \\
\hline & GO:0035639 & purine ribonucleoside triphosphate binding & $459(15.79 \%)$ & $2020(13.2 \%)$ & 0.000337 \\
\hline & GO:0000166 & nucleotide binding & $546(18.78 \%)$ & $2449(16 \%)$ & 0.000337 \\
\hline & GO:1901265 & nucleoside phosphate binding & $546(18.78 \%)$ & $2449(16 \%)$ & 0.000337 \\
\hline & GO:0005524 & ATP binding & 409 (14.07\%) & 1787 (11.67\%) & 0.000484 \\
\hline Cellular Component & GO:0005634 & nucleus & 160 (18.69\%) & 760 (14.36\%) & 0.021341 \\
\hline \multicolumn{6}{|l|}{ Trans regulation } \\
\hline \multirow[t]{3}{*}{ Cellular Component } & GO:0005618 & cell wall & $15(6.47 \%)$ & $104(1.97 \%)$ & 0.006155 \\
\hline & GO:0071944 & cell periphery & $21(9.05 \%)$ & $193(3.65 \%)$ & 0.006695 \\
\hline & GO:0030312 & external encapsulating structure & $15(6.47 \%)$ & $115(2.17 \%)$ & 0.006695 \\
\hline Biological Process & GO:0055114 & oxidation-reduction process & $95(15.97 \%)$ & $1187(10.36 \%)$ & 0.005702 \\
\hline
\end{tabular}

(Additional file 4) showed that the cis-regulated target genes of these lncRNAs were enriched in the tryptophan metabolism and alpha-linolenic acid metabolism pathways, and the trans-regulated target genes were enriched in the phenylalanine metabolism, carotenoid biosynthesis and alpha-linolenic acid metabolism pathways. These metabolic pathways participate in plant hormone synthesis. The antisense-regulated target genes were most highly enriched in plant hormone signal transduction.

We explored the lncRNAs that regulated mRNAs in the phytohormone synthesis and signal transduction pathways, and a detailed description of this information is provided in Additional file 5. Interestingly, 165 lncRNAs were involved in regulating the expression of genes in the plant hormone signal transduction pathway. In this pathway, 5.26, 5.72 and $9.62 \%$ of the lncRNAs, exhibited cis regulation, trans regulation and antisense regulation, respectively (Table 2 ).

\section{Regulation of IncRNAs and transcription factors in the plant hormone response during TW formation}

Six differentially expressed mRNAs involved in plant hormone biosynthesis and signal transduction were potentially regulated by cis-regulatory lncRNAs (Fig. 8). Because cis regulation requires the co-expression of lncRNAs and mRNAs, we further analyzed the correlations between the expression of these lncRNAs and mRNAs. This analysis revealed a strong correlation between ARF2 (evm.model.scaffold249.45) expression and

Table 2 Number of mRNAs regulated by IncRNAs in the hormone biosynthesis and signal transduction pathways

\begin{tabular}{|c|c|c|c|c|c|}
\hline \multirow[t]{2}{*}{ Pathway } & \multirow[t]{2}{*}{ Description } & \multirow{2}{*}{$\begin{array}{l}\text { Pathway } \\
\text { ID }\end{array}$} & \multicolumn{3}{|c|}{ The pattern of IncRNA regulation } \\
\hline & & & Cis & Trans & Antisense \\
\hline Carotenoid biosynthesis & ABA biosynthesis & ko00906 & $16(0.75 \%)$ & $9(1.39 \%)$ & $2(1.28 \%)$ \\
\hline Brassinosteroid biosynthesis & BR biosynthesis & ko00905 & $5(0.23 \%)$ & $3(0.46 \%)$ & $1(0.64 \%)$ \\
\hline Cysteine and methionine metabolism & ETH biosynthesis & ko00270 & $29(1.35 \%)$ & $10(1.55 \%)$ & $3(1.92 \%)$ \\
\hline Diterpenoid biosynthesis & GA biosynthesis & ko00904 & $12(0.56 \%)$ & $5(0.77 \%)$ & 0 \\
\hline Tryptophan metabolism & IAA biosynthesis & ko00380 & $19(0.88 \%)$ & $6(0.93 \%)$ & 0 \\
\hline alpha-Linolenic acid metabolism & JA biosynthesis & ko00592 & $24(1.12 \%)$ & $10(1.55 \%)$ & $4(2.56 \%)$ \\
\hline Phenylalanine metabolism & SA biosynthesis & ko00360 & $16(0.75 \%)$ & $8(1.24 \%)$ & $3(1.92 \%)$ \\
\hline Zeatin biosynthesis & ZT biosynthesis & ko00908 & $12(0.56 \%)$ & $5(0.77 \%)$ & $1(0.64 \%)$ \\
\hline Plant hormone signal transduction & Hormone signal transduction & ko04075 & $113(5.26 \%)$ & $37(5.72 \%)$ & $15(9.62 \%)$ \\
\hline
\end{tabular}




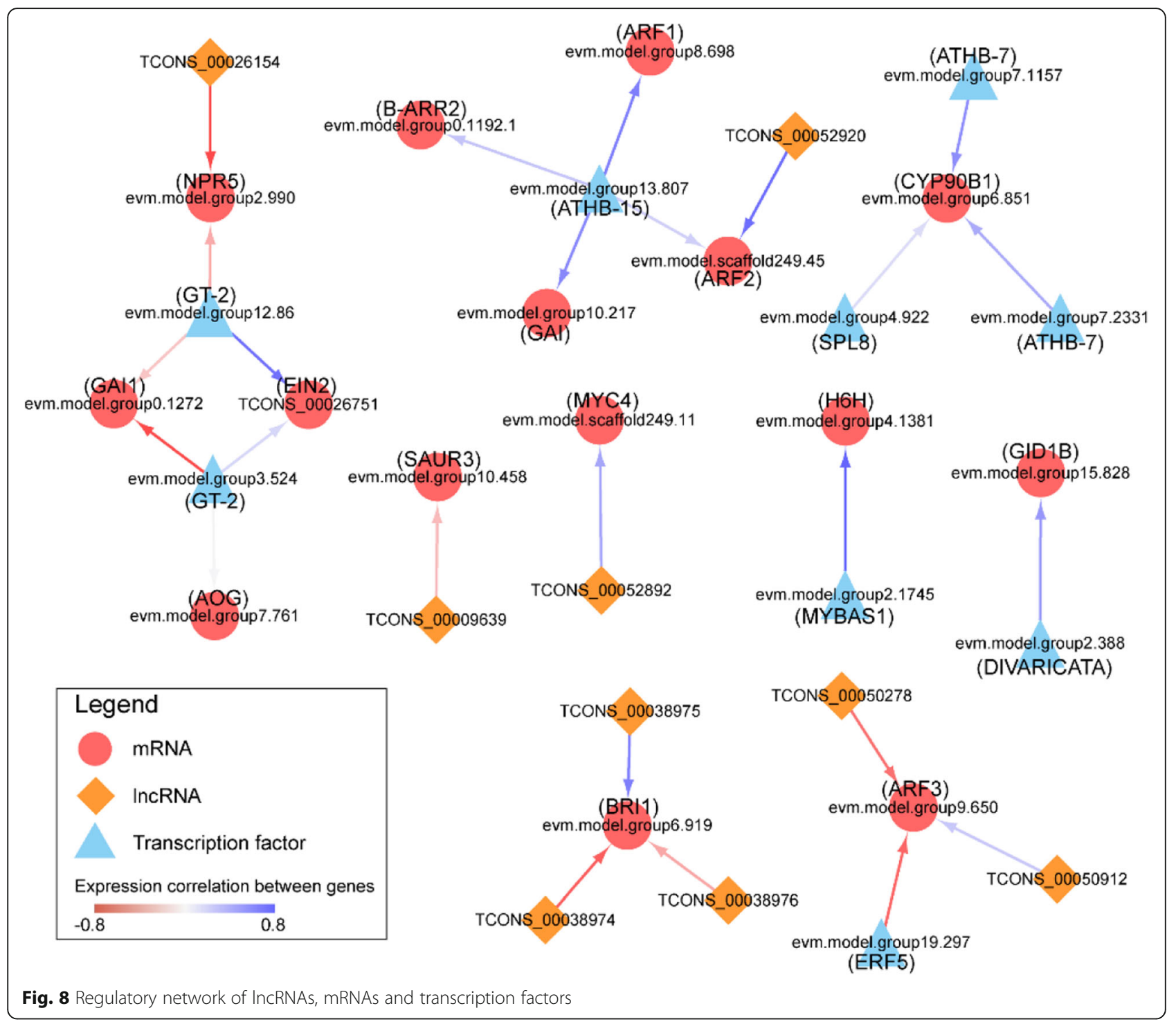

TCONS_00052920 expression (0.75). In addition, potential correlations between cis regulatory factors were observed between the BR signaling receptor gene BRII (evm.model.group6.919) and three novel lncRNAs (TCONS_00038974, TCONS_00038975, and TCONS_ 00038976), but only TCONS_00038975 exhibited a strong positive correlation with evm.model.group6.919 (0.65). This pattern implied that TCONS_00052920 and TCONS_00038975 may be novel lncRNAs regulatingTW formation in C. bungei.

In addition, we explored the differentially expressed transcription factors (DETFs) that regulate these DEGs to construct a regulatory network (Additional file 6, Fig. 8). Most DETFs were positively correlated with the DEGs. The transcription factor ATHB-15 (evm.model.group13.807) regulated four target genes and was strongly positively correlated with two of them, ARF1 (evm.model.group8.698) and GAI (evm.model.group10.217). Moreover, the CYP90B1 (evm.model.group6.851) gene exhibited a potential regulatory relationship with three transcription factors, two of which belong to the HD-ZIP transcription factor family.

\section{qRT-PCR analysis}

The expression levels of selected genes involved in plant hormone biosynthesis and signal transduction were measured using qRT-PCR to validate the results of the DEGs (Fig. 9). qRT-PCR results were consistent with the RNAseq data, indicating that these genes were precisely the key players in regulating the phytohormone content, phytohormone response and induction of TW formation in C. bungei. In addition, the results of the quantitative fluorescence analysis of IncRNAs showed that the relative expression of only the TCONS_00050278 gene was 


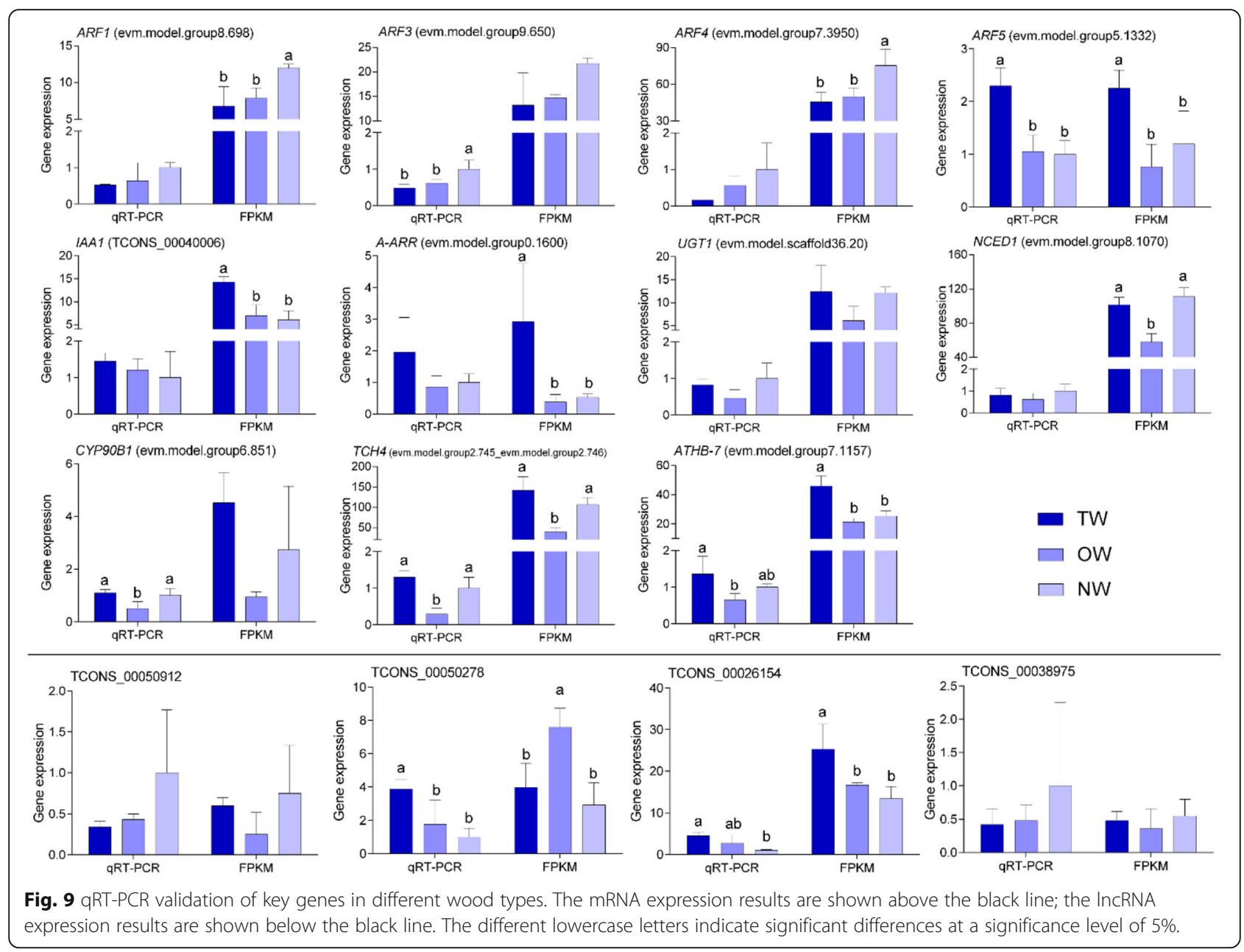

different from the result obtained using RNA-seq, while the expression patterns of the other three lncRNAs in the three wood types were relatively consistent with the sequencing results.

\section{Phytohormones mediated TW formation in C. bungei}

Based on the results described above, we constructed a multiple hormone-mediated regulatory network of TW formation in C. bungei (Fig. 10). Mechanical stimulation induced the expression of genes involved in the IAA and BR biosynthesis pathways to alter the phytohormone content. In addition, the balance of IAA contents between the upper and lower stem was disrupted. It induced the expression of ATHB transcription factors and lncRNAs to regulate plant hormone signal transduction and activate their target genes (A-ARR, ARF and TCH4), and modulate the chemical and physical properties of fibers. At the same time, these changes altered the differentiation pattern of vessels and the cell division ability of cambium to decrease the lignification process in the stress area.

\section{Discussion}

In our study, the vessels were smaller, and the vessel length:width ratio was significantly larger in TW than in OW and NW. Previous studies also confirmed that TW has smaller and longer vessels $[10,14]$. In addition, the TW of C. bungei had a thinner secondary wall without a G-layer. This result is consistent with the absence of the $\mathrm{G}$ and S3 layers and the thinner cell walls observed in two Magnoliaceae species [31]. Moreover, the TW exhibited lower lignification than OW and NW according to the Raman spectra and microscopy images. According to earlier reports, both the results of the spectroscopic analysis and chemical analysis indicate a lower lignin content in TW than in OW or NW [31-33]. Fibers resulting from low lignification may be a prerequisite for the increase in of the growth stress [33].

We detected a higher IAA content in TW than in OW. We speculate that the synthesis of IAA in OW maybe significantly reduced, or that more IAA is transported to TW. This result was similar to the findings reported by Hellgren et al. (2004), who indicated that the endogenous IAA content did not differ 


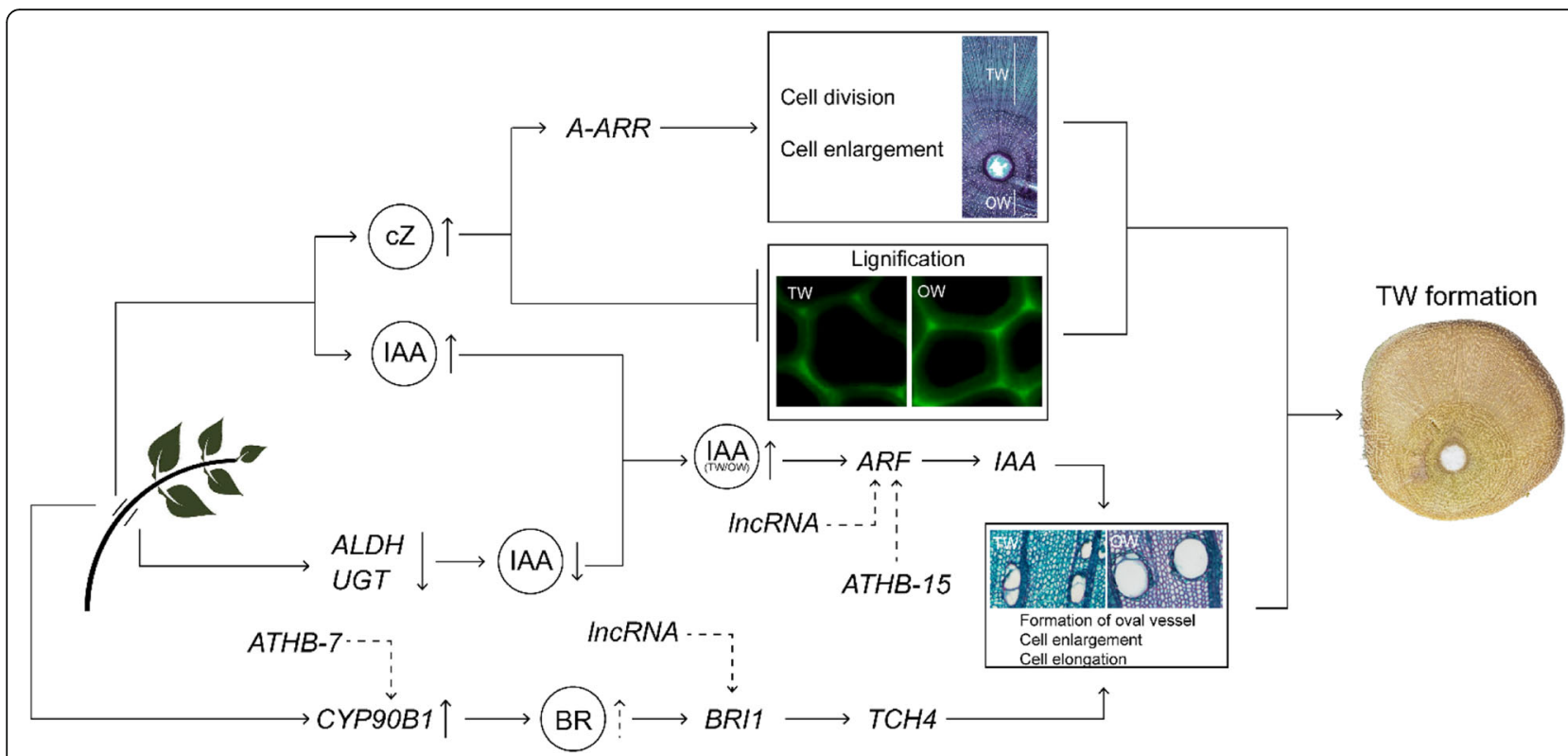

Fig. 10 The proposed model of the mechanism by which multiple phytohormones regulate TW formation in C. bungei. The dotted line indicates the predicted result

between NW and TW in $P$. tremula, although $\mathrm{OW}$ contained less IAA than TW according to LC-MS data [23]. The cZ content in TW was also significantly higher than in OW and NW. As a cytokinin, cZ regulates cell proliferation. Cytokinins regulate vascular tissue differentiation and cell wall lignification [34-37]. The increased $\mathrm{cZ}$ content in TW may explain why the increase in the cell layers in the upper stem triggers eccentric growth and decreases lignification. Cytokinins usually cooperate with auxin to regulate xylem development [38]. According our results, significantly higher levels of both IAA and cZ were detected in TW than in OW, and these hormones may coordinately control TW formation. Furthermore, OW contained the highest GA1 level, while TW contained the highest GA7 level. According to reports, most GAs do not have biological activity but GA1, GA3, GA4 and GA7 are the major bioactive GAs, [39] and they may participate in TW formation. The effect of gibberellin on TW formation has also been reported. Jiang et al. (2008) wherein GA3 and GA4 were exogenously applied to seedling of Fraxinus mandshurica, which resulted in negative geotropism and promoted G-layer formation in the fiber cell lumen [40]. According to Wang et al. (2017), gibberellin signaling induces RGA protein degradation, thus activating PtFLA6 gene expression and promoting TW formation in poplar [20]. Collectively, these results indicate that gibberellin is a positive factor regulating TW formation. However, our results did not indicate whether gibberellin was the key hormone regulating TW formation or its effects on TW formation in C. bungei, because the level of bioactive gibberellin varied among the wood types.

The $A-A R R$ gene PtRR7 is usually highly expressed in the vascular cambium in poplar [37]. FBR12 negatively regulates the expression of AtAHP6, AtARR15 and AtARR16 by forming a complex with CRE1 and AHP1 to inhibit xylem formation in Arabidopsis thaliana [41]. In the present study, the expression of $A-A R R$ and $C R E$, $A H P$ and $B-A R R$ genes was upregulated and downregulated in TW, respectively. Based on the results of the studies described above, we speculated that a cytokinin (cZ) may activate the $A-A R R$ gene in $C$. bungei and negatively regulate the expression of $B-A R R$ gene to modulate cxylem development in TW. The BRI1 and $\mathrm{TCH} 4$ genes related to $\mathrm{BR}$ signaling were significantly differentially expressed in TW compared with NW or OW. Additionally, the CYP90B1, which catalyzes the synthesis of BR, was significantly upregulated in TW compared with OW. Thus, BR signaling may regulate TW formation. PtCYP85A3, which is the gene encoding a key rate-limiting enzyme in BR synthesis, is overexpressed in poplar and increases the height and radial growth without changing the cell wall thickness [42]. This finding confirms that BR is related to plant stem cell division and elongation. Recent reports have also shown that an exogenous BR treatment increases the xylem area, alters carbohydrate deposition, and increases the expression of cell wall differentiation-associated genes to promote TW formation in poplar [43-45]. Interestingly, $\mathrm{TCH} 4$ responds to mechanical stimulation 
and is regulated by steroids, and its expression is significantly associated with cell enlargement [46]. Xyloglucan endotransglycosylases (XETs) encoded by TCH4 modify lignin polymers to alter the properties of the cell wall, such asextensibility and tensile strength [47]. In the present study, the activation of TCH4 in the TW of $C$. bungei may have changed the physical properties of the fiber cell wall. This relationship may be one of the key links in the mechanism underlying TW formation. Unfortunately, endogenous BR levels were not determined in this experiment.

The IAA content and the expression of genes involved in IAA biosynthesis and signal transduction were significantly different between TW and NW or OW in C. bungei. For instance, the ALDH1, UGT1, IAA1 and ARF5 genes were all upregulated in TW compared with NW or OW. Four ARFs were downregulated in TW compared with NW. As shown in the study by $\mathrm{Yu}$ et al. (2017), exogenous IAA increased the expression of the IAA transport-related genes PIN1, $A B C B 1$, and $A U X 2$, accelerating the polar transport of auxin and inducing TW formation [22]. Hellgren et al. (2004) did not observe significant differences int the endogenous IAA concentration in the cambium between TW and NW; thus, IAA was considered to have no correlation with TW formation [23]. However, Gerttula et al. (2015) found that the expression of the PIN3 at a specific location changed auxin polar transport, which was one of the mechanisms underlying TW formation, and this mechanism was regulated by gibberellin signaling [28]. ARF5 plays an important role in the early stage of vascular formation in A. thaliana and participates in multiple developmental processes, including vascular development in leaves and embryos, by directly activating the expression of ATHB8 and PIN1 [48-50]. Moreover, auxin can regulate the expression of the $\mathrm{BR}$ receptor gene, and BR utilizes the ARF7 and IAA19 to regulate this downstream process $[51,52]$. Notably, a significantly higher IAA level was detected in TW than in OW, and at the same time, the genes involved in the responses to IAA and BR signaling were also significantly differentially expressed during TW formation. Thus, IAA and BR might coordinate to control TW formation in $C$. bungei.

Gene expression is often regulated by intrinsic molecules. The mutation and regulation of lncRNAs play a key role in the expression of functional genes [53]. Here, we performed a preliminary analysis of the relationship between the expression of some lncRNAs and key genes. In our study, some DEGs (evm.model.scaffold249.45, evm.model.group6.919) involved in plant hormone biosynthesis and signal transduction were potential targets of IncRNAs (TCONS_00052920 and TCONS_00038975) through cis-regulation, according to the prediction of targeted relationships and the coexpression analysis. In addition, the transcription factor ATHB-15 and other HD-ZIP transcription factor family members were positively correlated with the DEGs related to IAA signal transduction. HD-ZIP transcription factors regulate several genes in the auxin signaling pathway, including the $A R F$ gene, to regulate plant embryonic development [54]. Moreover, the auxin response factors BDL and MP/ARF5 are coexpressed with HD-ZIP transcription factors during vascular development in $A$. thaliana embryos [55]. Thus, in our study, the changes in the expression of the ATHB-15 transcription factor in the HD-ZIP family may be dependent on the participation of auxin in vascular development of TW.

\section{Conclusion}

In this study, various plant hormones participated in $C$. bungei TW formation. Our results revealed a multiple hormone-mediated network regulating TW formation in C. bungei. TW exhibits significantly higher IAA and cZ contents than OW and NW; these plant hormone signals induced the expression of genes involved in IAA, $\mathrm{cZ}$ and BR signal transduction pathways. At the same time, some lncRNAs and transcription factors regulate the expression of some of the genes that were activated. Finally, these genes modulate the development of vessels and fibers in TW. This result provides a new basis for explaining the mechanisms of phytohormone-mediated TW formation.

\section{Methods}

\section{Plant material}

The tested C. bungei plants were grown at the experimental forest base at the Biandanzhao village (Luoyang, Henan, China; $\left.112^{\circ} 33^{\prime} \mathrm{E}, 34^{\circ} 43^{\prime} \mathrm{N}\right)$. The C. bungei clone 8402 was grafted at the end of April 2017, and plants were bent at a consistent angle of $45^{\circ}$ for 3 months to induce TW formation. The samples were taken from a height of $60 \mathrm{~cm}$ after bark removal. Samples from control plants (plants that were not subjected to bending) were collected at the same height. Information about the C. bungei specimens is available on the National $\mathrm{Mu}$ seum of Natural History website: http://coldb.mnhn.fr/ catalognumber/mnhn/p/p03532196. The deposition number is $\mathrm{P} 03532196$.

The parts that grew away from the center of the circle and stained blue-green with fast green were TW. The opposite properties were observed for OW (Fig. 11.). The tissues of each sample were divided according to the staining results of the sections. Five different individual plant samples were combined, and biological triplicates were used in subsequent experiments. 


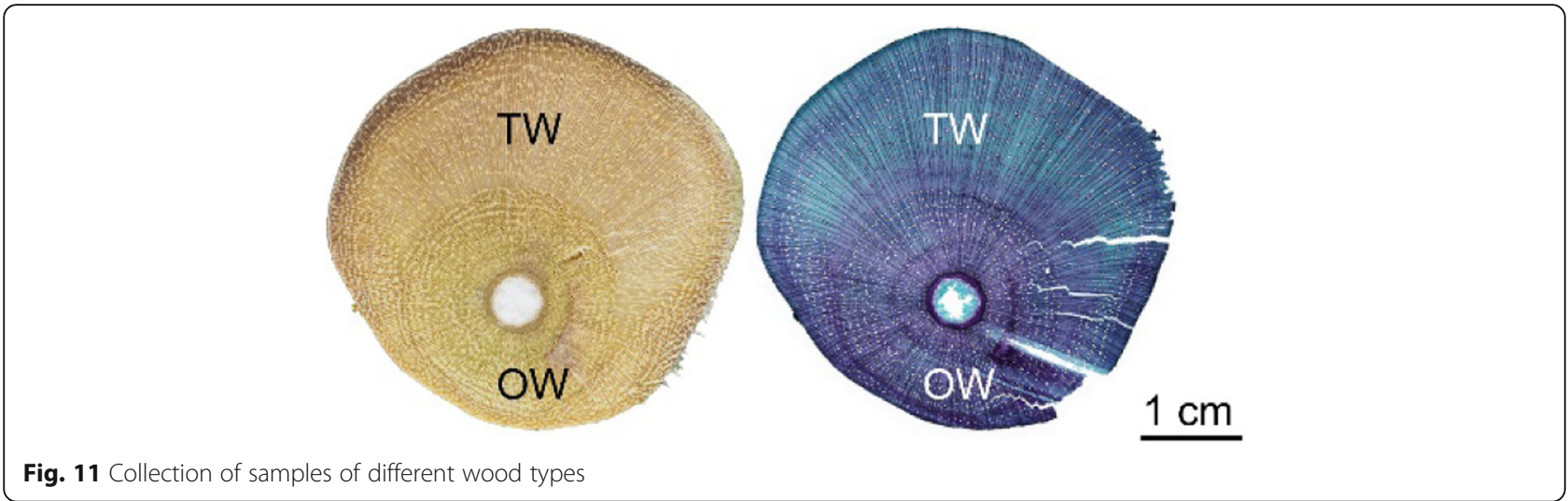

\section{Anatomy of xylem}

Leica SM2010 R slicing microtome was used to produce the $30-\mu \mathrm{m}$ xylem slices, which were incubated with $1 \%$ safranine dye for $12 \mathrm{~h}$ and dehydrated in a series of 30, 50, 75, and 95\% ethanol and anhydrous ethanol solutions. The slices were then incubated with $0.1 \%$ fast green dye for $4 \mathrm{~min}$ and sealed with Canadian resin. The sizes of the fibers and vessels (fiber cell wall thickness and vessel length and width) in the xylem of TW, OW and NW were measured in 3 individual plants. One hundred fifty cells from 5 microscopic fields were randomly counted from TW, OW and NW in each individual plant, and 450 cells were evaluated for each wood type.

\section{Confocal Raman microscopy and Raman mapping}

Tissue sections of the stem were imaged with a LabRam Xplora confocal Raman microscope (Horiba Jobin-Yvon, Paris, France) and an Olympus confocal microscope (Olympus, Tokyo, Japan) equipped with a linearly polarized $532 \mathrm{~nm}$ laser (Ventus VIS 532, Laser Quantum. A detailed description of the test procedures is provided in a previous study [56].

\section{LC-MS analysis of plant hormones}

(1) Sample preparation and extraction: Fresh xylem samples were harvested, weighed, immediately frozen in liquid nitrogen, and stored at $-80^{\circ} \mathrm{C}$ until further use. Plant materials (120 mg fresh weight) were frozen in liquid nitrogen, ground into powder, and extracted with methanol:water $(8: 2)$ at $4{ }^{\circ} \mathrm{C}$. The extract was centrifuged at $12000 \times \mathrm{g}$ at $4{ }^{\circ} \mathrm{C}$ for $15 \mathrm{~min}$. The supernatant was collected and was evaporated to dryness under a nitrogen gas stream and reconstituted in methanol: water (3:7). The solution was centrifuged, and the supernatant was collected for the LC-MS analysis.

(2) High-performance liquid chromatography (HPLC): Extracts of the xylem samples were analyzed using an LC-ESI-MS/MS system (HPLC, Shim-pack UFLC SHIM ADZU CBM30A system, www.shimadzu.com.cn/; MS, Applied Biosystems 6500 Triple Quadrupole, www. appliedbiosystems.com.cn/). The analysis conditions were as follows: HPLC column, Waters ACQUITY UPLC HSS T3 C18 $(1.8 \mu \mathrm{m}, 2.1 \mathrm{~mm} \times 100 \mathrm{~mm})$; solvent system, water $(0.04 \%$ acetic acid):acetonitrile $(0.04 \%$ acetic acid); gradient program, 95:5 V:V at $0 \mathrm{~min}, 5: 95 \mathrm{~V}$ : $\mathrm{V}$ at $11.0 \mathrm{~min}, 5: 95 \mathrm{~V}: \mathrm{V}$ at $12.0 \mathrm{~min}, 95: 5 \mathrm{~V}: \mathrm{V}$ at $12.1 \mathrm{~min}$, and $95: 5 \mathrm{~V}: \mathrm{V}$ at $15.0 \mathrm{~min}$; flow rate, $0.35 \mathrm{~mL} / \mathrm{min}$; temperature, $40{ }^{\circ} \mathrm{C}$; and injection volume: $5 \mu \mathrm{L}$. The effluent was alternatively connected to an electrospray ionization (ESI)-triple quadrupole linear ion trap ( $Q$ TRAP) mass spectrometer.

(3) ESI-Q TRAP-MS/MS: An API 6500 Q TRAP LCMS/MS system equipped with an ESI Turbo Ion Spray interface, operating in positive ion mode and controlled by Analyst 1.6 software (AB Sciex) was used. The ESI source operation parameters were as follows: ion source, turbo spray; source temperature, $500^{\circ} \mathrm{C}$; ion spray (IS) voltage, $5500 \mathrm{~V}$; curtain gas (CUR), $35.0 \mathrm{psi}$; and collision gas (CAD), medium. The declustering potential (DP) and collision energy $(\mathrm{CE})$ of individual multiple reaction monitoring (MRM) transitions were calculated, with further DP and CE optimization. A specific set of MRM transitions was monitored for each period according to the plant hormones eluted within this period.

\section{Illumina high-throughput sequencing of mRNAs and IncRNAs}

Total RNA was extracted from the TW, OW and NW using an RNA reagent kit (DP441; Tiangen Biotech, Beijing, China) according to the manufacturer's protocol. Nine transcriptome libraries were constructed for 150bp paired-end Illumina high-throughput sequencing of mRNAs and lncRNAs using the Illumina HiSeq ${ }^{\text {Tn }} 4000$ platform (Illumina, USA) by Gene Denovo Biotechnology Co. (Guangzhou, China). The post sequencing data filtering and analysis methodology have been described in a previous study [57]. Cufflinks and Cuffcompare software $[58,59]$ were used to assemble transcripts and compare sequences to known sequences in the $C$. bungei genome (unpublished). The fragments per kilobase of 
transcript per million mapped reads (FPKM) value was used as an indicator to evaluate gene expression [59]. In the present study, transcripts with a fold change of $\geq 1.5$ or $\leq-1.5$ and a $P$ value of $<0.05$ between various comparison groups were considered significant DEGs.

\section{Identification of IncRNAs}

Three network databases were used to predict the protein-coding ability of the transcripts: CPC (http:// www.mybiosoftware.com/cpc-0-9r2-assess-protein-coding\%2D\%2Dpotential-transcripts.html) (Kong et al. 2007), txCdspredict (http://hgdownload.soe.ucsc.edu/ admin/jksrc.zip) [60], and CNCI (https://github.com/ www-bioinfo-org/CNCI) [61]. In addition, IncRNAs were distinguished from mRNAs according to the thresholds. In the CPC and CNCI databases, the score thresholds were $\geq 0$ for mRNA and $<0$ for lncRNAs, and in txCdspredict, the thresholds were $\geq 500$ for mRNAs and $<500$ for lncRNAs. In addition, the Pfam database was used to further distinguish the mRNAs and lncRNAs, transcripts that were aligned to this protein database were predicted to be mRNAs, and transcripts that were not aligned were considered lncRNAs [62]. Transcripts that satisfied at least three predicted results were identified as lncRNAs.

\section{Regulatory relations between IncRNAs and mRNAs}

Notably, lncRNAs usually regulate target genes in three ways: proximal regulation, which is termed cis-acting regulation; remote regulation, which is termed transacting regulation; and antisense regulation. The lncRNAs located upstream or within $20 \mathrm{~kb}$ downstream of an mRNA were identified as cis-acting lncRNAs. We analyzed the binding energy of the lncRNAs and mRNAs using RNAplex [63] software. The lncRNAs with a binding energy of $<30$ and a distance of greater than $20 \mathrm{~kb}$ from their target mRNA were identified as trans-acting lnRNAs. Pearson's correlation coefficients were calculated to evaluate coexpression relationships between lncRNAs and mRNAs. The software RNAplex (http:// www.tbi.univie.ac.at/RNA/RNAplex.1.html) was used to predict the complementary correlations of antisense lncRNAs with mRNAs. The program includes the ViennaRNA package, and the prediction of the best base pairing was based on the calculation of the minimum free energy from the thermodynamic structure.

\section{qRT-PCR}

The total RNA used for qRT-PCR was the same as the sample used for RNA-seq. qRT-PCR was performed in a 7500 Real-Time PCR System (Applied Biosystems, CA, USA) using TB Green Premix Ex Taq ${ }^{\mathrm{TM}}$ (TaKaRa, Dalian, China) according to the manufacturer's instructions. The $2^{-\Delta \Delta C t}$ method was used to calculate the relative expression levels [64]. The actin gene of $C$. bungei served as the reference gene, and detailed primer information is shown in Additional file 7.

\section{Statistical analysis and graphical presentation}

The $R$ program was used to measure significance with ANOVA and Duncan's multiple comparisons tests. GraphPad 5 and Adobe Illustrator CS6 software were used to generate the figures. MultiExperiment Viewer software was used to construct the heat map of gene expression. The regulatory network was constructed using Cytoscape software.

\section{Supplementary information}

Supplementary information accompanies this paper at https://doi.org/10. 1186/s12864-020-07044-5.

Additional file 1: Table S1. The wood properties of different clones of C. bungei.

Additional file 2: Table S2 Number of different types of IncRNAs.

Additional file 3: Table S3 The annotation of DEGs involved hormone biosynthesis and signal transduction.

Additional file 4: Figure S1 KEGG pathway enrichment analysis of IncRNA target genes. (A) cis regulation, (B) trans regulation, (C) antisense regulation

Additional file 5: Table S4 The annotation of genes regulated by potential IncRNAs through cis regulation. Table S5 The annotation of genes regulated by potential IncRNAs via trans regulation. Table S6 The annotation of genes regulated by potential IncRNAs via antisense regulation

Additional file 6: Table S7 The annotation of genes regulated by IncRNAs and transcription factors in the regulatory network. Table $\mathbf{S 8}$ The correlations between the expression of genes and regulators.

Additional file 7: Table S9 Primer information.

\section{Abbreviations}

TW: Tension wood; OW: Opposite wood; NW: Normal wood; LC-MS: Liquid chromatography-mass spectrometry; IncRNA: Long noncoding RNA; Glayer: Gelatinous layer; KEGG: Kyoto Encyclopedia of Genes and Genomes; DEGs: Differentially expressed genes; FPKM: Fragments per kilobase of transcript per million mapped reads

\section{Acknowledgements}

We thank Dr. Wenjun Ma for identification of the plant material.

\section{Authors' contributions}

YX, JHW and WJM designed the research. FY, KZ and GJY performed the sample collection. JJL and JCW carried out the qRT- PCR experiments. YX, NL and ZRJ analyzed the data. YX wrote the paper. All authors discussed the results and contributed to the final manuscript. The authors read and approved the final manuscript

\section{Funding}

This work is supported by a National Key Research and Development Project of China "The genomic basis of secondary growth in trees"

(2016YFD0600101).

\section{Availability of data and materials}

The transcriptome sequence data have been deposited to the NCBI via Sequence Read Archive (SRA) with the accession numbers: PRJNA559964.

Ethics approval and consent to participate Not applicable. 


\section{Consent for publication}

Not applicable.

\section{Competing interests}

The authors declare that they have no competing interests

\section{Author details}

${ }^{1}$ State Key Laboratory of Tree Genetics and Breeding, Key Laboratory of Tree Breeding and Cultivation of State Forestry and Grassland Administration, Research Institute of Forestry, Chinese Academy of Forestry, Beijing 100091, PR China. ${ }^{2}$ Luoyang Academy of Agriculture and Forestry Science, Luoyang 471002, Henan Province, China.

Received: 22 April 2020 Accepted: 1 September 2020

Published online: 05 September 2020

\section{References}

1. Wardrop $A B$, Dadswell HE. The nature of reaction wood I. structure and properties of tension wood fibres. Aust J Biol Sci. 1948;1:3-16.

2. Wardrop $A B$, Scaife E. Occurrence of peroxidase in tension wood of angiosperms. Nature. 1956;178(4538):867.

3. Du S, Yamamoto F. An overview of the biology of reaction wood formation. J Integr Plant Biol. 2007;49(2):131-43.

4. Wilson BF, Gartner BL. Lean in red alder (Alnus rubra): growth stress, tension wood, and righting response. Can J For Res. 1996:26(11):1951-6.

5. Clair B, Ruelle J, Thibaut B. Relationship between growth stress, mechanicalphysical properties and proportion of fibre with gelatinous layer in chestnut (Castanea Sativa mill.). Holzforschung. 2003;57(2):189-95.

6. Yamamoto H, Abe K, Arakawa Y, Okuyama T, Gril J. Role of the gelatinous layer (G-layer) on the origin of the physical properties of the tension wood of Acer sieboldianum. J Wood Sci. 2005;51(3):222-33.

7. Bygdell J, Srivastava V, Obudulu O, Srivastava MK, Nilsson R, Sundberg B, Trygg J, Mellerowicz EJ, Wingsle G. Protein expression in tension wood formation monitored at high tissue resolution in Populus. J Exp Bot. 2017; 68(13):3405-17.

8. Lafarguette F, Leplé J-C, Déjardin A, Laurans F, Costa G, Lesage-Descauses M-C, Pilate G. Poplar genes encoding fasciclin-like arabinogalactan proteins are highly expressed in tension wood. New Phytol. 2004;164(1):107-21.

9. Yamamoto H. Generation mechanism of growth stresses in wood cell walls: roles of lignin deposition and cellulose microfibril during cell wall maturation. Wood Sci Technol. 1998;32(3):171-82.

10. Jourez B, Riboux A, Leclercq A. Anatomical characteristics of tension wood and opposite wood in young inclined stem of poplar (Populus euramericana CV 'GHOY'). IAWA J. 2001;22(2):133-57.

11. Lee PW, Eom YG. Anatomical comparison between compression wood and opposite wood in a branch of Korean pine (Pinus koraiensis). IAWA Bulletin. 1988:9(3):275-84.

12. Lin JX, Li ZL. Comparative anatomy of normal wood and compression wood of masson pine (Pinus massoniana). J Integr Plant Biol. 1993;35(3):201-5.

13. Clair B, Gril J, Renzo FD, Yamamoto H, Quignard F. Characterization of a gel in the Cell Wall to elucidate the paradoxical shrinkage of tension wood. Biomacromolecules. 2008;9(2):494-8.

14. Seyfferth C, Wessels BA, Gorzsas A, Love JW, Ruggeberg M, Delhomme N, Vain $T$, Antos $K$, Tuominen $H$, Sundberg B, et al. Ethylene signaling is required for fully functional tension wood in hybrid Aspen. Front Plant Sci. 2019;10:1101.

15. Love J, Bjorklund S, Vahala J, Hertzberg M, Kangasjarvi J, Sundberg B. Ethylene is an endogenous stimulator of cell division in the cambial meristem of Populus. PNAS. 2009;106(14):5984-9.

16. Felten J, Vahala J, Love J, Gorzsas A, Ruggeberg M, Delhomme N, Lesniewska J, Kangasjarvi J, Hvidsten TR, Mellerowicz EJ, et al. Ethylene signaling induces gelatinous layers with typical features of tension wood in hybrid aspen. New Phytol. 2018;218(3):999-1014

17. Du S, Uno H, Yamamoto F. Roles of auxin and gibberellin in gravity-induced tension wood formation in Aesculus turbinata seedlings. IAWA J. 2004;25(3):337-47.

18. Funada R, Miura T, Shimizu Y, Kinase T, Nakaba S, Kubo T, Sano Y. Gibberellin-induced formation of tension wood in angiosperm trees. Planta. 2008;227(6):1409-14.

19. Nugroho WD, Yamagishi Y, Nakaba S, Fukuhara S, Begum S, Marsoem SN, $\mathrm{Ko} \mathrm{JH}$, Jin $\mathrm{HO}$, Funada R. Gibberellin is required for the formation of tension wood and stem gravitropism in Acacia mangium seedlings. Ann Bot. 2012; 110(4):887-95.

20. Wang $H$, Jin $Y$, Wang $C$, Li B, Jiang C, Sun Z, Zhang Z, Kong F, Zhang $H$. Fasciclin-like arabinogalactan proteins, PtFLAs, play important roles in GAmediated tension wood formation in Populus. Sci Rep. 2017;7(1):6182.

21. Jiang S, Li YF, Chen HX, Xu K. Control of negative Gravitropism and tension wood formation by Gibberellic acid and Indole acetic acid in Fraxinus mandshurica Rupr. Var. japonica maxim seedlings. J Integr Plant Biol. 2006; 48(2):161-8.

22. Yu M, Liu K, Liu S, Chen H, Zhou L, Liu Y. Effect of exogenous IAA on tension wood formation by facilitating polar auxin transport and cellulose biosynthesis in hybrid poplar (Populus deltoids $\times$ Populus nigra) wood. Holzforschung. 2017;71(2):179-88.

23. Hellgren JM, Olofsson $K$, Sundberg B. Patterns of auxin distribution during gravitational induction of reaction wood in poplar and pine. Plant Physiol. 2004;135(1):212-20.

24. Moyle R, Schrader J, Stenberg A, Olsson O, Saxena S. Environmental and auxin regulation of wood formation involves members of the aux/IAA gene family in hybrid aspen. Plant J. 2002;31(6):675-85.

25. Chen J, Chen B, Zhang D. Transcript profiling of Populus tomentosa genes in normal, tension, and opposite wood by RNA-seq. BMC Genomics. 2015;16:164.

26. Cai M, Huang H, Ni F, Tong Z, Lin E, Zhu M. RNA-Seq analysis of differential gene expression in Betula luminifera xylem during the early stages of tension wood formation. Peer J. 2018;6:e5427.

27. Xiao Y, Yi F, Ling J, Wang Z, Zhao K, Lu N, Qu G, Kong L, Ma W, Wang J. Transcriptomics and proteomics reveal the cellulose and pectin metabolic processes in the tension wood (non-G-layer) of Catalpa bungei. Int J Mol Sci. 2020;21:1686.

28. Gerttula S, Zinkgraf M, Muday GK, Lewis DR, Ibatullin FM, Brumer H, Hart F, Mansfield SD, Filkov V, Groover A. Transcriptional and hormonal regulation of Gravitropism of Woody stems in Populus. Plant Cell. 2015;27(10):2800-13.

29. Chen J, Quan M, Zhang D. Genome-wide identification of novel long noncoding RNAs in Populus tomentosa tension wood, opposite wood and normal wood xylem by RNA-seq. Planta. 2015;241(1):125-43.

30. Xiao Y, Ma WJ, Lu N, Wang Z, Wang N, Zhai WJ, Kong LS, Qu GZ, Wang QX, Wang JH. Genetic Variation of Growth Traits and Genotype-by-Environment Interactions in Clones of Catalpa bungei and Catalpa fargesii f. duclouxii. Forests. 2019;10(1):57.

31. Yoshizawa N, Inami A, Miyake S, Ishiguri F, Yokota S. Anatomy and lignin distribution of reaction wood in two Magnolia species. Wood Sci Technol. 2000;34(3):183-96.

32. Mizrachi E, Maloney VJ, Silberbauer J, Hefer CA, Berger DK, Mansfield SD, Myburg AA. Investigating the molecular underpinnings underlying morphology and changes in carbon partitioning during tension wood formation in Eucalyptus. New Phytol. 2014;206(4):1351-63.

33. Yoshida M, Ohta H, Yamamoto H, Okuyama T. Tensile growth stress and lignin distribution in the cell walls of yellow poplar, Liriodendron tulipifera Linn. Trees. 2002;16(7):457-64.

34. Herrero J, Esteban Carrasco A, Zapata JM. Arabidopsis thaliana peroxidases involved in lignin biosynthesis: in silico promoter analysis and hormonal regulation. Plant Physiol Biochem. 2014;80:192-202.

35. Matsumoto-kitano M, Kusumoto T, Tarkowski P, Kinoshitatsujimura K, Václavíková K, Miyawaki K, Kakimoto T. Cytokinins are central regulators of cambial activity. PNAS. 2008;105(50):20027-31.

36. Moritz T, Sundberg B. Endogenous cytokinins in the vascular cambial region of Pinus sylvestris during activity and dormancy. Physiol Plant. 2006;98(4):693-8.

37. Nieminen K, Immanen J, Laxell M, Kauppinen L, Tarkowski P, Dolezal K, Tähtiharju S, Elo A, Decourteix M, Ljung K, et al. Cytokinin signaling regulates cambial development in poplar. PNAS. 2008;105(50):20032-7.

38. Bishopp A, Help H, El-Showk S, Weijers D, Scheres B, Friml J, Benkova E, Mahonen AP, Helariutta Y. A mutually inhibitory interaction between auxin and cytokinin specifies vascular pattern in roots. Curr Biol. 2011;21(11):917-26.

39. Yamaguchi S. Gibberellin metabolism and its regulation. Annu Rev Plant Biol. 2008;59:225-51.

40. Jiang $S, X u$ K, Wang YZ, Ren YP, Gu S. Role of GA3, GA4 and uniconazole-P in controlling gravitropism and tension wood formation in Fraxinus mandshurica Rupr. Var. japonica maxim. Seedlings. J Integr Plant Biol. 2008;50(1):19-28.

41. Delay C, Imin N, Djordjevic MA. Regulation of Arabidopsis root development by small signaling peptides. Front Plant Sci. 2013;4:352.

42. Jin $Y L$, Tang $R J$, Wang HH, Jiang CM, Bao Y, Yang Y, Liang MX, Sun ZC, Kong FJ, Li B, et al. Overexpression of Populus trichocarpa CYP85A3 promotes 
growth and biomass production in transgenic trees. Plant Biotechnol J. 2017;15(10):1309-21.

43. Du J, Gerttula S, Li ZH, Zhao ST, Liu YL, Liu Y, Lu MZ, Groover AT. Brassinosteroid regulation of wood formation in poplar. New Phytol. 2020; 225(4):1516-30.

44. Gao J, Yu M, Zhu S, Zhou L, Liu S. Effects of exogenous 24-epibrassinolide and brassinazole on negative gravitropism and tension wood formation in hybrid poplar (Populus deltoids X Populus nigra). Planta. 2019;249(5):1449-63.

45. Yuan H, Zhao L, Guo W, Yu Y, Tao L, Zhang L, Song X, Huang W, Cheng L, Chen J, et al. Exogenous Application of Phytohormones Promotes Growth and Regulates Expression of Wood Formation-Related Genes in Populus simonii X P. nigra. Int J Mol Sci. 2019;20(3):792.

46. Iliev EA, Xu W, Polisensky DH, Oh MH, Torisky RS, Clouse SD, Braam J. Transcriptional and posttranscriptional regulation of Arabidopsis TCH4 expression by diverse stimuli. Roles of cis regions and brassinosteroids. Plant Physiol. 2002;130(2):770-83.

47. Campbell P, Braam J. Xyloglucan endotransglycosylases: diversity of genes, enzymes and potential wall-modifying functions. Trends Plant Sci. 1999;4(9):361-6.

48. Hardtke CS, Ckurshumova W, Vidaurre DP, Singh SA, Stamatiou G, Tiwari SB, Hagen G, Guilfoyle TJ, Berleth T. Overlapping and non-redundant functions of the Arabidopsis auxin response factors MONOPTEROS and NONPHOTOTROPIC HYPOCOTYL 4. Development. 2004;131(5):1089-100.

49. Lau S, De Smet I, Kolb M, Meinhardt H, Jurgens G. Auxin triggers a genetic switch. Nat Cell Biol. 2011;13(5):611-5.

50. Scarpella E, Marcos D, Friml J, Berleth T. Control of leaf vascular patterning by polar auxin transport. Genes Dev. 2006;20(8):1015-27.

51. Sakamoto T, Fujioka S. Auxins increase expression of the brassinosteroid receptor and brassinosteroid-responsive genes in Arabidopsis. Plant Signal Behav. 2013;8(4):e23509.

52. Zhou X-Y, Song L, Xue H-W. Brassinosteroids regulate the differential growth of Arabidopsis hypocotyls through Auxin signaling components IAA19 and ARF7. Mol Plant. 2013;6(3):887-904.

53. Kim ED, Sung S. Long noncoding RNA: unveiling hidden layer of gene regulatory networks. Trends Plant Sci. 2012;17(1):16-21.

54. Roodbarkelari F, Groot EP. Regulatory function of homeodomain-leucine zipper (HD-ZIP) family proteins during embryogenesis. New Phytol. 2017;213(1):95-104

55. Hamann T, Benkova E, Baurle I, Kientz M, Jurgens G. The Arabidopsis BODENLOS gene encodes an auxin response protein inhibiting MONOPTEROS-mediated embryo patterning. Genes Dev. 2002;16(13):1610-5.

56. Ma J, Zhou X, Ma J, Ji Z, Zhang X, XU F. Raman microspectroscopy imaging study on topochemical correlation between lignin and hydroxycinnamic acids in Miscanthus sinensis. Microsc Microanal. 2014;20(3):956-63.

57. Li CY, Deng GM, Yang J, Viljoen A, Jin Y, Kuang RB, Zuo CW, Lv ZC, Yang QS, Sheng O. Transcriptome profiling of resistant and susceptible Cavendish banana roots following inoculation with Fusarium oxysporum f. sp. cubense tropical race 4. BMC Genomics. 2012;13:374.

58. Chen M, Xu R, Ji H, Greening DW, Rai A, Izumikawa K, Ishikawa H, Takahashi $\mathrm{N}$, Simpson RJ. Transcriptome and long noncoding RNA sequencing of three extracellular vesicle subtypes released from the human colon cancer LIM1863 cell line. Sci Rep. 2016;6:38397.

59. Trapnell C, Williams BA, Pertea G, Mortazavi A, Kwan G, van Baren MJ, Salzberg SL, Wold BJ, Pachter L. Transcript assembly and quantification by RNA-Seq reveals unannotated transcripts and isoform switching during cell differentiation. Nat Biotechnol. 2010;28(5):511-5.

60. Sun $\mathrm{K}$, Chen X, Jiang P, Song X, Wang H, Sun H. iSeeRNA: identification of long intergenic non-coding RNA transcripts from transcriptome sequencing data. BMC Genomics. 2013;14(Suppl 2):S7.

61. Sun L, Luo H, Bu D, Zhao G, Yu K, Zhang C, Liu Y, Chen R, Zhao Y. Utilizing sequence intrinsic composition to classify protein-coding and long noncoding transcripts. Nucleic Acids Res. 2013;41(17):e166.

62. Burge SW, Daub J, Eberhardt R, Tate J, Barquist L, Nawrocki EP, Eddy SR, Gardner PP, Bateman A. Rfam 11.0: 10 years of RNA families. Nucleic Acids Res. 2013;41:226-32.

63. Tafer H, Hofacker IL. RNAplex: a fast tool for RNA-RNA interaction search. Bioinformatics. 2008;24(22):2657-63.

64. Livak KJ, Schmittgen TD. Analysis of relative gene expression data using real-time quantitative PCR and the 2(-Delta Delta $C(T))$ method. Methods. 2001:25(4):402-8.

\section{Publisher's Note}

Springer Nature remains neutral with regard to jurisdictional claims in published maps and institutional affiliations.
Ready to submit your research? Choose BMC and benefit from:

- fast, convenient online submission

- thorough peer review by experienced researchers in your field

- rapid publication on acceptance

- support for research data, including large and complex data types

- gold Open Access which fosters wider collaboration and increased citations

- maximum visibility for your research: over $100 \mathrm{M}$ website views per year

At $\mathrm{BMC}$, research is always in progress.

Learn more biomedcentral.com/submissions 